BMJ Open Sport \& Exercise Medicine

\title{
Lessons from a broad view of science: a response to Dr Robergs' article
}

\author{
Flavio Oliveira Pires
}

To cite: Pires F0. Lessons from a broad view of science: a response to $\mathrm{Dr}$ Robergs' article. BMJ Open Sport \& Exercise Medicine 2018;4:e000353. doi:10.1136/ bmjsem-2018-000353

Accepted 25 February 2018

Check for updates

Exercise Psychophysiology Research Group, School of Arts, Sciences and Humanities, University of São Paulo, São Paulo, Brazil

Correspondence to Dr Flavio Oliveira Pires; piresfo@usp.br

\section{ABSTRACT}

Dr Robergs suggested that the central governor model (CGM) is not a well-worded theory, as it deviated from the tenant of falsification criteria. According to his view of science, exercise researches with the intent to prove rather than disprove the theory contribute little to new knowledge and condemn the theory to the label of pseudoscience. However, exercise scientists should be aware of limitations of the falsification criteria. First, the number of potential falsifiers for a given hypothesis is always infinite so that there is no mean to ensure asymmetric comparison between theories. Thus, assuming a competition between CGM and dichotomised central versus peripheral fatigue theories, scientists guided by the falsification principle should know, a priori, all possible falsifiers between these two theories in order to choose the finest one, thereby leading to an oversimplification of the theories. Second, the failure to formulate refutable hypothesis may be a simple consequence of the lack of instruments to make crucial measurements. The use of refutation principles to test the CGM theory requires capable technology for online feedback and feedforward measures integrated in the central nervous system, in a real-time exercise. Consequently, falsification principle is currently impracticable to test CGM theory. The falsification principle must be applied with equilibrium, as we should do with positive induction process, otherwise Popperian philosophy will be incompatible with the actual practice in science. Rather than driving the scientific debate on a biased single view of science, researchers in the field of exercise sciences may benefit more from different views of science.

\section{INTRODUCTION}

I read Dr Robergs' article ${ }^{1}$ with much enthusiasm, from the first to the last paragraph. He criticised my occasional piece article suggesting a probable Kuhnian paradigm shift in exercise sciences. ${ }^{2}$ I was expecting comments and critiques to my provocative essay since its publication, approximately 5 years ago. Perhaps, as philosophy of science is complex and purely reflexive, just a few exercise scientists have devoted enough time to study it. Now I have the opportunity to continue debating and applying some philosophy in the exercise sciences perspective.

Reading Dr Robergs' ${ }^{1}$ article drove me back to the philosophy of science to re-examine some crucial academic work essential to a broader understanding of how science operates. Since my first critical essay as a beginner student in science, about The Objective Knowledge of Karl Popper ${ }^{3}$ during lectures on philosophy of science by Emeritus Professor Michel Paty at the University of São Paulo, I have come through different views of science, from Francis Bacon to Karl Popper, from Thomas Kuhn to Paul Feyerabend. Thus, the biased commentary promoted by Dr Robergs towards the falsification method did not surprise me because Karl Popper was one of the first philosophers I read as a beginner in science. Neither was Dr Robergs' ${ }^{1}$ claim in favour of the falsification criteria in exercise sciences entirely new. ${ }^{4}$ As a philosophy-oriented scientist, I learnt that we may benefit from a wider view of science as there is no infallible mode to understand science whatsoever. The falsification method assumptions may have implications on how we conceive the scientific development in exercise sciences, nevertheless omitted by Dr Robergs. In a Popperian perspective, the need to oversimplify a theory (ie, the falsification principle asymmetry), and accept past experiences to formulate falsifiable hypothesis (thus falling back in induction), should be considered as limitations, when in the context of the debate on exercise sciences.

As it is beyond the scope of this rebuttal to present all pros and cons relative to different views of science, I encourage beginners in exercise sciences to read different views of science in full; this will enable them to adopt a more critical position in scientific debates. This would be of value to understand the points I highlight below about the weaknesses of Dr Robergs' article.

\section{Problems of the falsification principle}

To criticise my earlier Kuhnian Paradigm Shift in Exercise Science essay, ${ }^{2}$ Dr Robergs classified Karl Popper as the most contemporary philosopher of science, the owner of 'the single valid approach to scientific method in exercise sciences'. ${ }^{1}$ According to Dr Robergs, 'Popper had a simplistic view of 
the delineation between science and pseudoscience, any non-critical application of science, that was not based on efforts at falsification, was pseudoscientific'. Curiously, Dr Robergs did not warn readers about important limitations of the falsification criteria.

Popper believed that the more falsifiable the hypothesis of a theory, the better the theory. ${ }^{5}$ However, the number of potential falsifiers for a given hypothesis is always infinite so that by no means can asymmetric comparison between theories be assured. In fact, some have argued that because falsification is never completely conclusive, the asymmetry of falsification principle proposed by Popper is actually impossible. ${ }^{5-7}$ For example, in 2012, ${ }^{2}$ I assumed that the growing acceptance of a centrally regulated effort theory would replace the dichotomised central versus peripheral fatigue theory (a Kuhnian perspective). In a Popperian perspective, exercise scientists guided by the falsification principle should know, a priori, all possible falsifiers between these two theories in order to choose the finest one. Because a given hypothesis of a theory can be false only if we take the theory as a whole in our test, the falsification of a theory is not a straightforward schema and, therefore, the application of falsification principle (in strict terms) in exercise sciences to test the central governor model (CGM) is consequently impracticable.

Moreover, the need to know all conditions met by the theory before testing a hypothesis forces scientists to oversimplify the theory since the knowledge of all conditions would be obviously possible only in simple conjectures. This controversy of falsification would drive the theory to a likely separation of its important components in order to create hypothesis possibly falsifiable. As a result, the application of the falsification method to test the CGM theory would lead, at least momentously, to an oversimplification of the exercise tolerance phenomenon. Remember, the CGM was formulated as a complex, non-linear, neurophysiological-psychological model of exercise performance. ${ }^{8-10}$ As stated by Duhem $\left(\right.$ apud Ladyman $\left.{ }^{5}\right) \quad$ using physics as an example, "physical science is a system that must be taken as a whole; it is an organism in which one part cannot be made to function except when the parts that are most remote from it are called into play, some more so than others, but all to some degree". Accordingly, Micklewright ${ }^{11}$ stated that "the CGM cannot be adequately tested by observing its components in isolation".

There are other two limitations of the falsification principle that readers must be aware. First, some statements cannot be experimentally falsifiable. ${ }^{5}$ A simple and embarrassing example is the following statement: 'time and space are infinite'. Logically, the falsification of such a statement is experimentally impossible. Therefore, a theory asserting the existence of a phenomenon cannot be automatically classified as pseudoscience if someone fails to apply the falsification method over it. Another limitation is that the failure to find a phenomenon under some circumstances or to formulate refutable hypothesis in experimental set-ups may be a simple consequence of the lack of instruments to make crucial measurements. ${ }^{5}$ An example of the need for instruments capable of measuring a given phenomenon was recently provided in physics. Parts of the gravitational waves theory have been confirmed many years after the theory was proposed. Accordingly, confirmation of the heliocentric theory initially proposed by Copernicus was confirmed later, after the telescope was invented. ${ }^{5}$ Regarding the CGM, some statements may not be falsified at the moment due to the lack of means for it. A technology capable of providing online feedback and feedforward measures integrated in the central nervous system, in a real-time exercise is crucial to use refutation principles when experimenting this theory.

Finally, some hypotheses may not be falsified simply because they can be part of a science that is seemingly unfalsifiable. ${ }^{5}$ For example, an unfalsifiable statement includes the uncertainty principle, which asserts that the more precise the determination of the position of some particle, the less precise the estimation of its momentum and vice versa. This principle is apparently unfalsifiable, as results that do not match a given estimation cannot work to refute the theory. In fact, the falsification principle is unable to deal with probabilistic statements, being an inconvenient mismatch between logic and observation in the falsification perspective. ${ }^{5}$ Although one may argue that the CGM theory does not fit to probabilistic statements, the knowledge of such a limitation is important to highlight that falsification principle is far for being a universal principle for philosophy of science. In fact, incredible progress observed in epidemiology and pharmacy sciences (among others) cannot be explained by falsification.

\section{We benefit more by using different philosophies of science}

I acknowledge that the critical rationalism embedded in the falsification method of Karl Popper could lead to a more critical and rational use of the scientific method in exercise sciences, as this may guide scientists to crucial questions and important investigations in some circumstances. Nonetheless, the falsification principle must be applied with equilibrium, just as we should do with positive induction process. Otherwise, Popperian philosophy will be incompatible with the actual practice in science.

Different from Dr Robergs' conclusion, Katch ${ }^{12}$ seemed to have referred to Karl Popper just to highlight the importance of inductive inferences derived from exclusion research. In my opinion, $\mathrm{Katch}^{12}$ did not affirm that 'Karl Popper was the philosopher who has contributed most to the understanding of the ideal tenants of the scientific method'. For example, when Dr Katch referred to experiments by Dr Brooks challenging the anaerobic threshold concept (Katch, p594), ${ }^{12}$ he suggested the use of 'disproofability' as a vein to provide answers to important questions, instead of a method to decide between rival theories. Katch ${ }^{12}$ wrote that "A new dimension to Wasserman hypothesis has been added that has made the hypothesis all the richer." In my opinion, 
he indicated that refutation provided by Dr Brooks was of value to improve hypotheses of the theory, rather than refute the theory as a whole. Therefore, although recognising that falsification principles may be of value to strengthen a given theory in some circumstances, we should be aware that they are only a critical mean to apply the scientific method occasionally. As argued above, this has nothing to do with a straightforward vein to set a theory as acceptable/valid, once the choice between rival theories may involve a more complex dilemma. Accordingly, the best scenario of falsification method in exercise sciences is to guide scientists when using the scientific method in critical enquiries. Therefore, the acceptance or rejection of the CGM theory based exclusively on the falsification criteria is not practicable.

It is important to point out that Popperian scientists make their initial judgements about a hypothesis based on proclaimed knowledge derived from prior theories and experimentations. Hence, Popperian scientists must accept past experiences to formulate falsifiable hypothesis, thus falling back in induction. Actually, a scientist can believe in empirical consequences of a given theory only if he believes in the truth of the background assumptions. Popperian scientists should consciously admit the use of induction process in their observations when proposing balanced experimentation, as induction processes are impossible to be left out from the scientific scenario. This is crucial for scientists intending to avoid ingenuous assumptions when formulating a hypothesis and its experimentation, otherwise a purely ingenuous Popperian approach may lead them to reject a theory and its predictions before having a better theory for replacement. This is what happens if we take Dr Robergs' suggestion integrally (despite arguing that CGM theory is a pseudoscience, he offered no alternative explanation for the phenomenon).

An important aspect that beginners in science should consider is that some have argued that the change of meaning of terms and logic is sometimes reasonable and more convenient than rejecting a particular theory. ${ }^{5}$ The atomic theory provides a simple example of a change of meaning of a term, as this theory first defined 'atom' as the least indivisible particle, however when scientists found that atom was divisible they redefined the meaning of atom in order to not abandon the theory. In this example, the use of naive and ingenuous falsification principles may have led scientists to abandon the atomic theory, thus blocking an incredible scientific progress in biology, chemistry and other sciences. Therefore, rather than abandoning the CGM theory, perhaps is time to redefine the meaning of some terms to refine the theory, as recently suggested elsewhere. ${ }^{1314}$ The final word about the acceptability of this theory belongs to the scientific community.

\section{The Kuhnian paradigm shift in exercise sciences}

I agree with Dr Robergs, "Kuhn did not write his text with the intention of presenting a model for how the scientific method, or science itself, should work" and neither did
I defend such a principle in my previous article. ${ }^{2}$ I am not sure about the implicit message left by Dr Robergs suggesting my Kuhnian approach was inadequate. ${ }^{1}$ As argued in my paper, a change has occurred as to how the exercise sciences community has focused on the limits of exercise tolerance. ${ }^{2}$ My suggestion of paradigm shift in exercise sciences was based on aspects that, together, may indicate a change of focus of the exercise sciences community and growing acceptance of a new theory.

Besides the omission of the work of Karl Popper, the most fundamental concern of Dr Robergs was the use of citation number in my essay (the argument that exercise physiology is not a discipline is irrelevant to this debate), since he considered that I used the number of citations by itself to infer acceptance of a topic/theory. He correctly argued that "Journal citations or topical preference cannot be interpreted as evidence of acceptance or agreement." Curiously, Dr Robergs omitted the fact that I used two other aspects together, to indicate a growing acceptance of a centrally regulated effort model. Thus, he misunderstood that I used the number of citations to indicate 'focus', rather than 'agreement or acceptance'. As I wrote in my previous article, " "number of citations about a specific theme could indicate the focus of a particular scientific community along time." Furthermore, in addition to number of citations I used, the number of views on specific websites as an indication of what the exercise sciences community has focused on.

Besides the number of citations (1), I pointed out that the increased debate on issues challenged by the CGM (2) and the inclination of the scientific community to incorporate a new interpretation (3) could indicate, together, a growing acceptance. I argued that traditional important journals of exercise sciences had published specific contents about fatigue mechanisms, highlighting central mechanisms that could be involved in the exercise regulation. Furthermore, important researchers involved with mechanisms of the traditional central versus peripheral fatigue dilemma had started to recognise the importance of integrative explanations for the limits of exercise tolerance. I further assumed that 'Perhaps, the most relevant is that scientists from different fields have highlighted mechanisms included in the CGM to understand the limits of exercise'. Therefore, different from what Dr Robergs suggested, ${ }^{1}$ I used three different aspects to indicate where the exercise sciences community has focused on, probably suggesting an intellectual trajectory towards the acceptance of a different theory.

According to a Kuhnian view of science, the degree of confirmation given by experimentation is not objective; therefore, no demarcation criteria can determine logically which theory is most justified by the evidence. ${ }^{6}{ }^{15}$ The scientific community as a whole regards the theory as justified. ${ }^{5}$ I wrote on page 2 of my paper ${ }^{2}$ that "the impossibility of performing neutral comparisons with standardized rules to determine the truth of a theory, labelled by Kuhn as 'incommensurability of theories', collective judgement is an important criterion to decide 


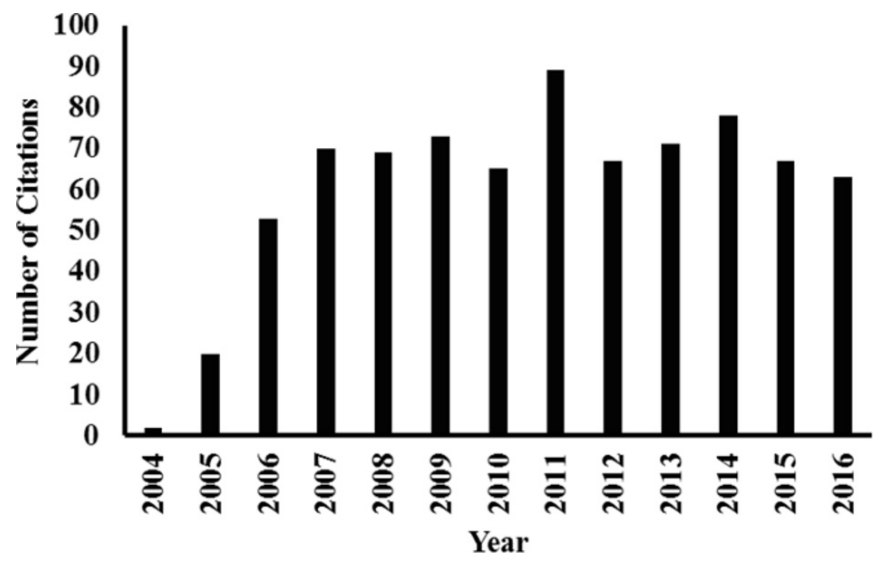

Figure 1 Citation report of all five articles proposing the central governor model ${ }^{8-101819}$ (accessed by www. webofknowledge.com on 11 October 2017).

between rival theories in the Kuhnian process". Thus, criteria 1, 2 and 3 together may suggest that the exercise sciences community has changed the focus toward a growing acceptance of a new, integrative theory.

\section{Updating the Kuhnan view in exercise sciences}

I agree that there is a flaw in my previous occasional piece, once I presented the number of citations of only two theoretical articles proposing the CGM theory. However, its proponents orchestrated this theory within five theoretical papers in an approach comparable to the elegant approach of Archibald V. Hill and colleagues almost 100 years earlier. ${ }^{16}{ }^{17}$ First, proponents of the CGM theory presented sequential arguments rebutting the current paradigm, ${ }^{18}$ thereafter they suggested a novel model of integrative central neural regulation..$^{8-10} 19$ Thus, instead of using two of these five theoretical reviews arbitrarily determined, all five prepositional studies should have been used. Encouraged by this debate, I present now an updated number of citations of these works (figure 1). It is important to warn readers that the number of citations by itself does not indicate too much, as others have presented relevant theoretical reviews with a high number of citations, but without changing the focus of the scientific community. Examples include the conservation of the traditional anaerobic threshold concept ${ }^{20}$ as originally proposed by Wasserman and Mcilroy, ${ }^{21}{ }^{22}$ even after evidences against this traditional paradigm, ${ }^{23}$ as well as the lactate-derived acidosis dilemma promoted by Dr Robergs. ${ }^{24}$ Hence, rather than the number of citation by itself, other marks should be used together to strengthen the argument in favour of a paradigm shift as proposed in 2012. ${ }^{2}$

An important result predicted by the Kuhnian Scientific Revolution is the incorporation of new terms by scientific community to characterise the new paradigm. ${ }^{5}$ In this regard, new terms have emerged since the original proposition of the CGM theory. Thus, perhaps it is time to use new terms to verify how the exercise sciences community has incorporated the CGM. For example, 'pacing strategy' and 'decision-making' may reflect the original ideas promoted by the CGM theory, as both constructs

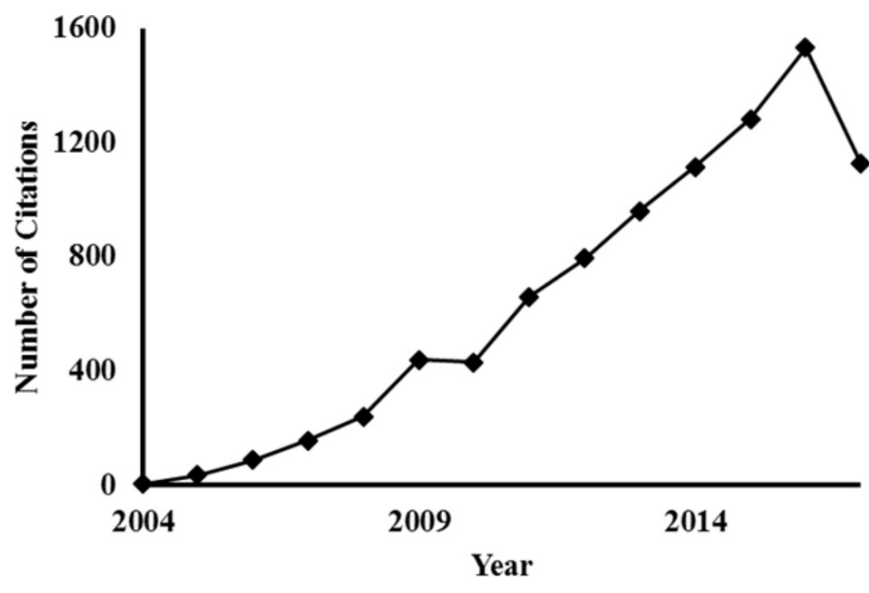

Figure 2 Citation report having 'central governor and exercise', 'pacing strategy and exercise' and 'decisionmaking and exercise' as truncated keywords (accessed by www.webofknowledge.com on 11 October 2017).

has been related to a centrally orchestrated neuropsychological regulation. ${ }^{25}{ }^{26}$ Although other terms could be also included to reflect the original CGM theory, it is beyond the aim of this article to present an updated list of new terms. Just as exemplification, I present the citation report having 'central governor and exercise', 'pacing strategy and exercise' and 'decision-making and exercise' as truncated keywords, therefore showing an increasing number of articles working with central, neuropsychological regulation concepts (figure 2). Thus, when compared with data presented in my first Kuhnian essay ${ }^{2}$ (figure 1), it is possible to note that concepts derived from the CGM theory have been used, increasingly.

Furthermore, as originally suggested in $2012,{ }^{2}$ there was an increased debate on issues challenged by the CGM (item 2 of the Kuhnian paper). Currently, important journals have still devoted relevant volumes to discuss concepts connected to this new paradigm. ${ }^{27} 28$ It is important to make clear that the present article is limited to discuss the probable Kuhnian Scientific Revolution in exercise sciences having the CGM as an example, thus it is beyond of this rebuttal to discuss other integrative interpretations to the exercise tolerance phenomenon, ${ }^{29} 30$ which appeared after the Kuhnian Scientific Revolution triggered by the CGM. ${ }^{8-1019}$ Actually, the appearance of other ways to interpret the phenomenon may be indicative of a Kuhnian Scientific Revolution.

\section{Additional concerns of Dr Robergs}

In his review, ${ }^{1}$ Dr Robergs included as an additional concern that proponents of CGM theory advocated the presence and function of a new brain location, which they referred to as the 'teleoanticipatory central nervous system'. Then, he claimed that CGM proponents 'provided no empirical evidence of this centre'. After several readings of the original theoretical CGM papers, I have never gone through such a question, since my understanding about the CGM theory was that the integrative regulation involves multiple physiological systems 
under the control of brain regulatory mechanisms in a dynamic and continuous interaction. ${ }^{13} 19$ The presence of a 'new' brain location was never my understanding, as I always considered a central governor as the central nervous system as a whole. Therefore, despite of its helplessness utility, the name 'Central Governor' seemed to be no more than a semantic choice.

Regarding the peer-review process mentioned by Dr Robergs, from my perspective as an independent author, I have seen theoretical articles in favour of ${ }^{14}$ as well as against ${ }^{31}$ this theory being published by this journal. Discussion about an 'open, double-visible' review process in scholarly journals is fruitful and demanded, but it is beyond the aim of this review.

\section{CONCLUSIONS}

Thomas Kuhn predicted that scientists attached to the old paradigm would resist to accept the new one. The scepticism of Dr Robergs to accept the CGM theory seems to belong to a different category-one based on ingenuous falsification principle. This category apparently matches with Thomas Kuhn's view of science, that is, 'The scientist who pauses to examine every anomaly he notes will seldom get significant work done'. ${ }^{5}$ Therefore, rather than driving the scientific debate on a biased single view of science, scientists of exercise sciences may benefit more from different views of science.

Funding This study was funded by the São Paulo Research Foundation (FAPESP 2016/16496-3).

Competing interests None declared.

Patient consent Not required.

Provenance and peer review Not commissioned; internally peer reviewed.

Open Access This is an Open Access article distributed in accordance with the Creative Commons Attribution Non Commercial (CC BY-NC 4.0) license, which permits others to distribute, remix, adapt, build upon this work non-commercially, and license their derivative works on different terms, provided the original work is properly cited and the use is non-commercial. See: http://creativecommons.org/ licenses/by-nc/4.0/

(c) Article author(s) (or their employer(s) unless otherwise stated in the text of the article) 2018. All rights reserved. No commercial use is permitted unless otherwise expressly granted.

\section{REFERENCES}

1. Robergs RA. Lessons from Popper for science, paradigm shifts, scientific revolutions and exercise physiology. BMJ Open Sport Exerc Med 2017;3:e000226.

2. Pires FO, de Oliveira Pires F. Thomas Kuhn's 'Structure of Scientific Revolutions' applied to exercise science paradigm shifts: example including the Central Governor Model. Br J Sports Med 2013;47:721-2.

3. Popper KR. Objective knowledge. Oxford: Claredon Press, 1972.

4. Noakes TD. Is it time to retire the A.V. Hill Model?: a rebuttal to the article by Professor Roy Shephard. Sports Med 2011;41:263-77.

5. Ladyman J. Understanding Philosophy of Science. London: Taylor \& Francis, 2002.

6. Kuhn T. The structure of scientific revolutions. Chicago: University of Chicago Press, 1962.
7. Feyerabend PK. Against method: outline of an Anarchistic Theory of Knowledge. Minneapolis: University of Minnesota Press, 1970.

8. Lambert EV, St Clair Gibson A, Noakes TD. Complex systems model of fatigue: integrative homoeostatic control of peripheral physiological systems during exercise in humans. Br J Sports Med 2005;39:52-62.

9. Noakes TD, St Clair Gibson A, Lambert EV. From catastrophe to complexity: a novel model of integrative central neural regulation of effort and fatigue during exercise in humans. Br J Sports Med 2004;38:511-4.

10. Noakes TD, St Clair Gibson A, Lambert EV. From catastrophe to complexity: a novel model of integrative central neural regulation of effort and fatigue during exercise in humans: summary and conclusions. Br J Sports Med 2005;39:120-4.

11. Micklewright $D$, Parry $D$. The central governor model cannot be adequately tested by observing its components in isolation. Sports Med 2010;40:91-2. author reply 92-4.

12. Katch V. "The burden of disproof.". Med Sci Sports Exerc 1986;18:593-5.

13. St Clair Gibson A, Swart J, Tucker R. The interaction of psychological and physiological homeostatic drives and role of general control principles in the regulation of physiological systems, exercise and the fatigue process - The Integrative Governor theory. Eur J Sport Sci 2018;18:25-36.

14. Venhorst A, Micklewright D, Noakes TD. Towards a threedimensional framework of centrally regulated and goal-directed exercise behaviour: a narrative review. Br J Sports Med 2017. 10.1136/bjsports-2016-096907. [Epub ahead of print 23 Aug 2017].

15. Kuhn T. The essential tension. Chicago: University of Chicago Press, 1977.

16. Hill AV, Lupton $\mathrm{H}$. Muscular exercise, lactic scid, and the supply and utilization of oxygen. Q J Med 1923;16:36.

17. Hill $\mathrm{AV}$, Long $\mathrm{CN}$, Lupton $\mathrm{H}$. The effect of fatigue on the relation between work and speed, in contraction of human arm muscles. J Physiol 1924;58(4-5):334-7.

18. Noakes TD, St Clair Gibson A. Logical limitations to the "catastrophe" models of fatigue during exercise in humans. $\mathrm{Br} J$ Sports Med 2004;38:648-9.

19. St Clair Gibson A, Noakes TD. Evidence for complex system integration and dynamic neural regulation of skeletal muscle recruitment during exercise in humans. $\mathrm{Br} J$ Sports Med 2004;38:797-806.

20. Meyer T, Lucía A, Earnest CP, et al. A conceptual framework for performance diagnosis and training prescription from submaximal gas exchange parameters - theory and application. Int J Sports Med 2005;26(Suppl 1):S38-48.

21. Wasserman K, Mcilroy MB. Detecting the threshold of anaerobic metabolism in cardiac patients during exercise. Am J Cardiol 1964;14:844-52.

22. Wasserman K, Whipp BJ, Koyl SN, et al. Anaerobic threshold and respiratory gas exchange during exercise. J Appl Physiol 1973;35:236-43.

23. Brooks GA. Anaerobic threshold: review of the concept and directions for future research. Med Sci Sports Exerc 1985;17:22-34.

24. Robergs RA, Ghiasvand F, Parker D. Biochemistry of exerciseinduced metabolic acidosis. Am J Physiol Regul Integr Comp Physiol 2004;287:R502-16.

25. Renfree A, Martin L, Micklewright D, et al. Application of decisionmaking theory to the regulation of muscular work rate during selfpaced competitive endurance activity. Sports Med 2014;44:147-58.

26. Smits BL, Pepping GJ, Hettinga FJ. Pacing and decision making in sport and exercise: the roles of perception and action in the regulation of exercise intensity. Sports Med 2014;44:763-75.

27. Meeusen R, Pires FO, Pinheiro FA, et al. Commentaries on viewpoint: a role for the prefrontal cortex in exercise tolerance and termination. J Appl Physiol 2016;120:467-9.

28. Hettinga FJ, Renfree A, Pageaux B, et al. Editorial: regulation of endurance performance: new Frontiers. Front Physiol 2017;8:727.

29. Marcora S. Perception of effort during exercise is independent of afferent feedback from skeletal muscles, heart, and lungs. J Appl Physiol 2009;106:2060-2.

30. Amann M. Central and peripheral fatigue: interaction during cycling exercise in humans. Med Sci Sports Exerc 2011;43:2039-45.

31. Weir JP, Beck TW, Cramer JT, et al. Is fatigue all in your head? A critical review of the central governor model. Br J Sports Med 2006;40:573-86. discussion 86. doi. 